\title{
Application of Porous Carbon Material As Electrode Material of Polyvalent Cation Electric Double Layer Capacitor (EDLC) for High Capacity
}

\author{
Tsubasa Okamura ${ }^{a}$, Kiyoharu Nakagawa ${ }^{\text {a }}$ b \\ a Department of Chemical, Energy and Environmental Engineering, Kansai University, \\ ${ }^{\mathrm{b}}$ High Technology Research Center of Kansai University
}

\begin{abstract}
Electric double layer capacitors (EDLC) are improved energy density by increasing the capacitance and potential. $\mathrm{Ca}^{2+}$ was used as the electrolyte to increase capacitance. Two electrons can be exchanged by using a divalent cation. The solvent is an organic solvent with a wide potential window. Propylene carbonate (PC) and $\gamma$-butyrolactone (GBL), which are commonly used in EDLC research, were used as the solvent. $\mathrm{Ca}^{2+}$ electrolyte has a high capacitance. In addition, the dependence of the specific surface area and pore characteristics of the electrode material on the capacity was examined. Activated carbon and carbon gel were used as electrode materials. The capacitance of $\mathrm{Ca}^{2+}$ electrolyte increased when GBL was used as the solvent. Capacitance increased depending on the specific surface area of electrode materials.
\end{abstract}

\section{Introduction}

Electric double layer capacitors (EDLC) are charged and discharged by the physical adsorption and desorption of electrolyte ions on the electrode surface ${ }^{1)}$. EDLC has the advantages of high-speed charge and discharge and long life ${ }^{1)}$. EDLC is used in memory backup power supplies such as personal computers and energy regenerative systems for power regenerative brakes in hybrid vehicles. In recent years, demand for applications such as in-vehicle power supplies has increased ${ }^{2)}{ }^{3)}$. Therefore, high energy density is required. The energy density increases by increasing the electrostatic capacity and the potential. In the conventional adsorption and desorption of monovalent cations, only one electron can be exchanged for each cation. In adsorption and desorption, two electrons can be exchanged for each cation. Therefore, it was considered that the capacitance can be increased by using an electrolyte of divalent cations.

In this study, $\mathrm{Ca}^{2+}$ was used as the divalent cation. As an organic electrolyte, propylene carbonate (PC) and $\gamma$-butyrolactone (GBL), which are commonly used in EDLC research as a solvent and can dissolve the electrolyte used. In addition, the dependence of the specific surface area and pore characteristics of the electrode material on the capacity was examined. Activated carbon and carbon gel were used as electrode materials.

\section{Experimental}

$\underline{\text { Preparation of electrolyte }}$ 
The electrolyte was prepared by dissolving lithium perchlorate $\left(\mathrm{LiClO}_{4}\right)$ and calcium perchlorate $\left(\mathrm{Ca}\left(\mathrm{ClO}_{4}\right)_{2}\right)$ in propylene carbonate $(\mathrm{PC})$ and $\gamma$-butyrolactone $(\mathrm{GBL})$, respectively, at a concentration of $1 \mathrm{~mol} / \mathrm{L}$.

\section{Creation of electrode sheet}

Activated carbon (AC) (YP50F, Kuraray Co., LTD.) and prepared ResorcinolFormaldehyde Carbon Xerogel (RFCX) ${ }^{4)}$ was used as the active material, carbon black (TOKABLACK, Tokaicarbon Co., LTD.) was used as the conductive additive, and Teflon resin was used as the binder. These were kneaded at a weight ratio of 8:1:1 and the diameter was $12 \mathrm{~mm}$ and the thickness was $0.1 \mathrm{~mm}$. A circular electrode sheet was prepared.

\section{Characterization of pore structures}

Nitrogen adsorption/desorption isotherms were measured at $77 \mathrm{~K}$ using automatic gas adsorption apparatus (Belsorp-mini, BELJAPAN, LTD.) to evaluate the pore structure of samples. The specific surface area and micropore volume were analyzed by the BET and MP methods, respectively. Mesopore volume and pore size distributions were calculated using the $\mathrm{BJH}$ and DA methods.

\section{Cyclic voltammetry measurement}

Two-electrode-cell (Figure 1.) was assembled in a glove box (under $\mathrm{N}_{2}$ atmosphere) with a humidity of $10 \%$ or less. The above electrodes and $200 \mu \mathrm{L}$ of electrolyte were used. Separator used Cellulose fiber (ADVANTEC Toyo, LTD.).

Cyclic voltammetry measurement was performed to calculate the capacitance using electrochemical measurement system (HZ-5000, Hokuto Denko, LTD.). The scanning potential was 0 to $3 \mathrm{~V}$ and the scan rate was $1 \mathrm{mV} / \mathrm{s}$ and $5 \mathrm{mV} / \mathrm{s}$.

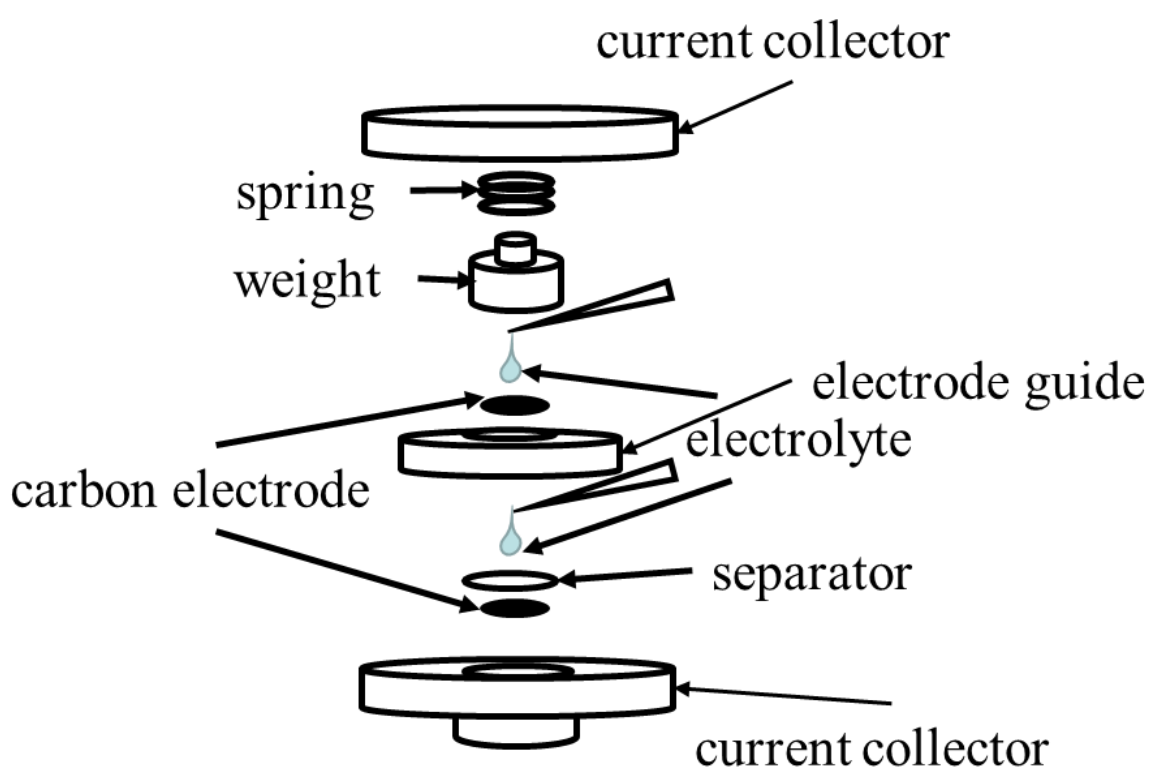

Figure 1 Two-electrode-cell used by electrochemical measurement 


\section{Evaluation of solvation structure between $\mathrm{Ca}^{2+}$ and each solvent}

The solvation structure between $\mathrm{Ca}^{2+}$ and each solvent was evaluated by Laser Raman spectrometry (NRS-3100, JASCO). The wavelength of the excitation laser light source was $532 \mathrm{~nm}$ and the laser power was $100 \mathrm{~mW}$. The measurement was conducted with an exposure time of $5 \mathrm{~s}$ and an integration number of 8 times. The wave number of the Raman shift was calibrated using silicon and polypropylene standards.

\section{Results and Discussion}

$\underline{\text { Pore characteristics of electrode materials }}$

The pore properties and pore size distributions of activated carbon and RFCX were shown in Table 1 and Figure 2, respectively. AC was a carbon material with a large specific surface area and many micropores. RFCX was a carbon material with a specific surface area which was about half area of AC and had many mesopores.

Table1 Pore properties of AC and RFCX

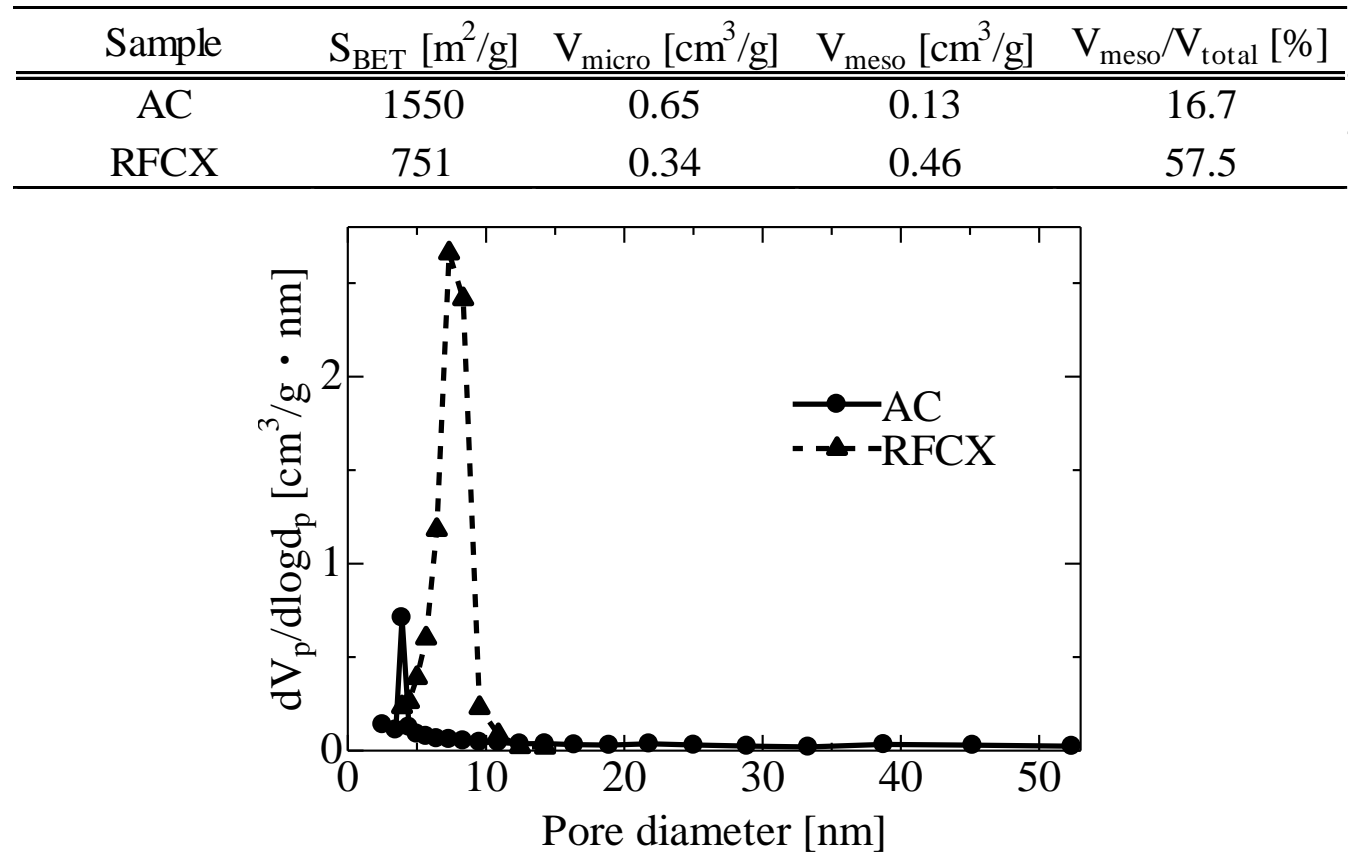

Figure 2 Pore size distributions of AC and RFCX

\section{Cyclic voltammetry measurement result}

Table 2 shows the capacitance of each electrolyte using AC was obtained from the $\mathrm{CV}$ measurement. $\mathrm{Ca}^{2+}$ electrolyte has a higher capacitance than that of $\mathrm{Li}^{+}$electrolyte. This is considered to be due to the transfer of two electrons. In addition, Capacitance using $\mathrm{Ca}^{2+}$ electrolyte increased using GBL was used as the solvent. This is considered to be due to the solvation structure of $\mathrm{Ca}^{2+}$, and will be discussed in the next chapter. However, Capacitance of $\mathrm{Ca}^{2+}$ electrolyte tended to decrease significantly when the scan rate was increased. 
Table 3 shows the capacitance of each electrode material when $\mathrm{Ca}\left(\mathrm{ClO}_{4}\right)_{2} / \mathrm{PC}$ was used as the electrolyte. It was found that the capacitance was high, depending on the specific surface area of the electrode materials, regardless of the pore size.

Figure 3 shows CV curves for each electrolyte using AC. The CV curve is said to form a better electric double layer as it approaches a rectangular shape ${ }^{5)}$. It can be considered the $\mathrm{CV}$ curve is close to a rectangular type regardless of which electrolyte is used, and thus an electric double layer having good charge/discharge characteristics was formed.

Table 2 The capacitance using AC of each electrolyte calculated from CV measurements

\begin{tabular}{cccc}
\hline \multirow{2}{*}{ Solvent } & Electrolytes & \multicolumn{2}{c}{ Capacitance $[\mathrm{F} / \mathrm{g}]$} \\
\cline { 3 - 4 } & & $1 \mathrm{mV} / \mathrm{s}$ & $5 \mathrm{mV} / \mathrm{s}$ \\
\hline \multirow{2}{*}{$\mathrm{PC}$} & $\mathrm{LiClO}_{4}$ & 79 & 65 \\
& $\mathrm{Ca}\left(\mathrm{ClO}_{4}\right)_{2}$ & 119 & 72 \\
\multirow{2}{*}{ GBL } & $\mathrm{LiClO}_{4}$ & 86 & 64 \\
& $\mathrm{Ca}\left(\mathrm{ClO}_{4}\right)_{2}$ & 176 & 85 \\
\hline
\end{tabular}

Table 3 The capacitance of AC and RFCX calculated from CV measurements

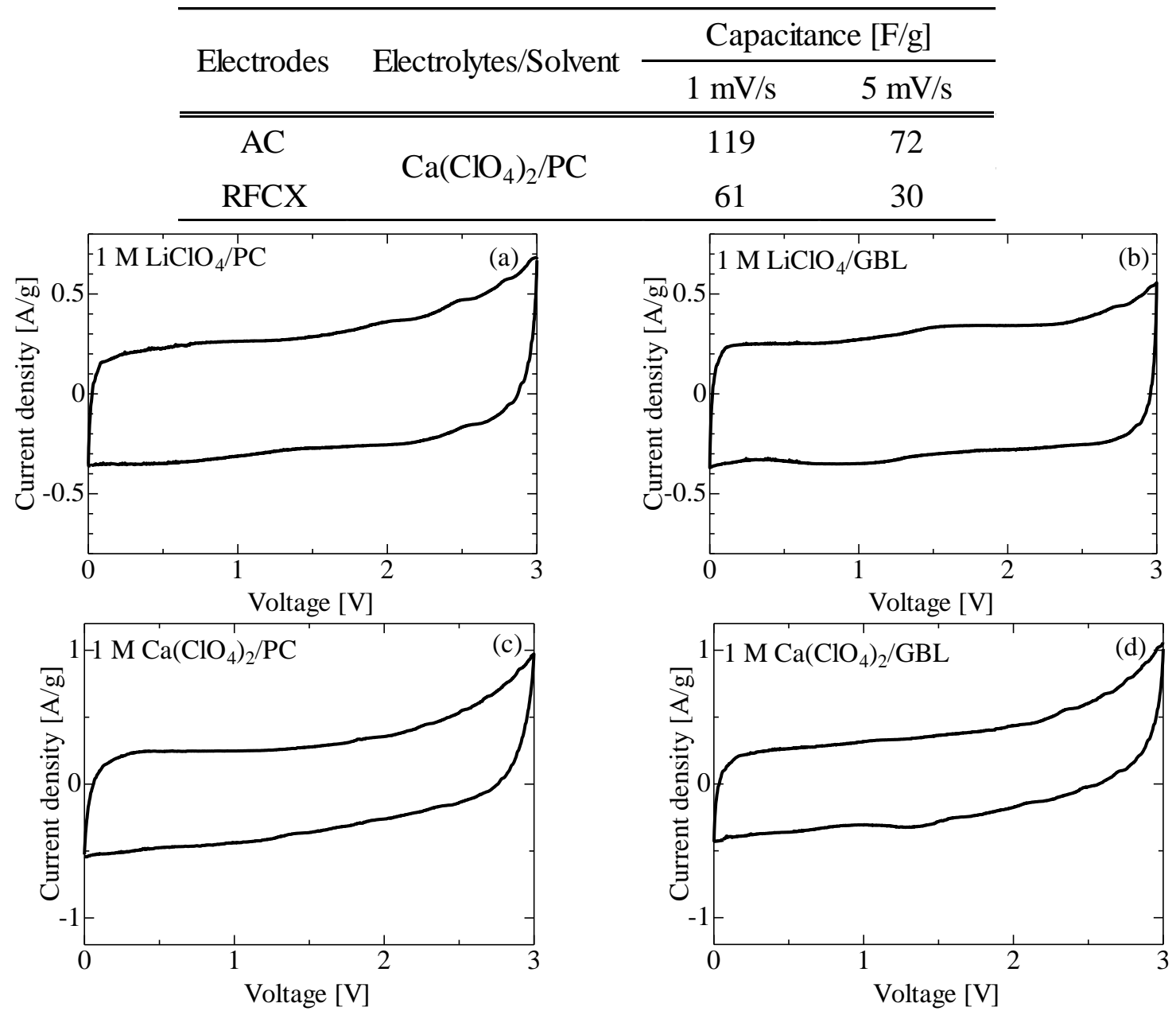

Figure $3 \mathrm{CV}$ curve at $5 \mathrm{mV} / \mathrm{s}$ using $\mathrm{AC}$ in (a) $1 \mathrm{M} \mathrm{LiClO}_{4} / \mathrm{PC}$ (b) $1 \mathrm{M} \mathrm{LiClO}_{4} / \mathrm{GBL}$ (c) $1 \mathrm{M} \mathrm{Ca}\left(\mathrm{ClO}_{4}\right)_{2} / \mathrm{PC}$ (d) $1 \mathrm{M} \mathrm{Ca}\left(\mathrm{ClO}_{4}\right)_{2} / \mathrm{GBL}$. 


\section{Evaluation of solvation structure of $\mathrm{Ca}^{2+}$}

The capacitance of $\mathrm{Ca}^{2+}$ electrolyte changed depending on the solvent. Figure 4 shows the Raman spectra of the $\mathrm{C}-\mathrm{O}$ stretching vibration in PC and GBL based electrolytes containing $\mathrm{Ca}\left(\mathrm{ClO}_{4}\right)_{2}$. PC appear in the spectrum at approximately $955 \mathrm{~cm}^{-1}$, When a $\mathrm{Ca}\left(\mathrm{ClO}_{4}\right)_{2}$ was dissolved, a new band was confirmed at about $930 \mathrm{~cm}^{-1}$. This band is derived from a solvent molecule coordinated to $\mathrm{Ca}^{2+}$ to form a solvated ion. On the other hand, the GBL solvent induces a band about $930 \mathrm{~cm}^{-1}$. Even if $\mathrm{Ca}\left(\mathrm{ClO}_{4}\right)_{2}$ was dissolved, no new bands were observed. Therefore, it is considered that $\mathrm{Ca}^{2+}$ has a small interaction with GBL and a small number of apparent coordination molecules ${ }^{6}$. It was suggested that when GBL was used as the solvent in the $\mathrm{Ca}^{2+}$ electrolyte, the amount of $\mathrm{Ca}^{2+}$ adsorbed increased and the capacitance increased.
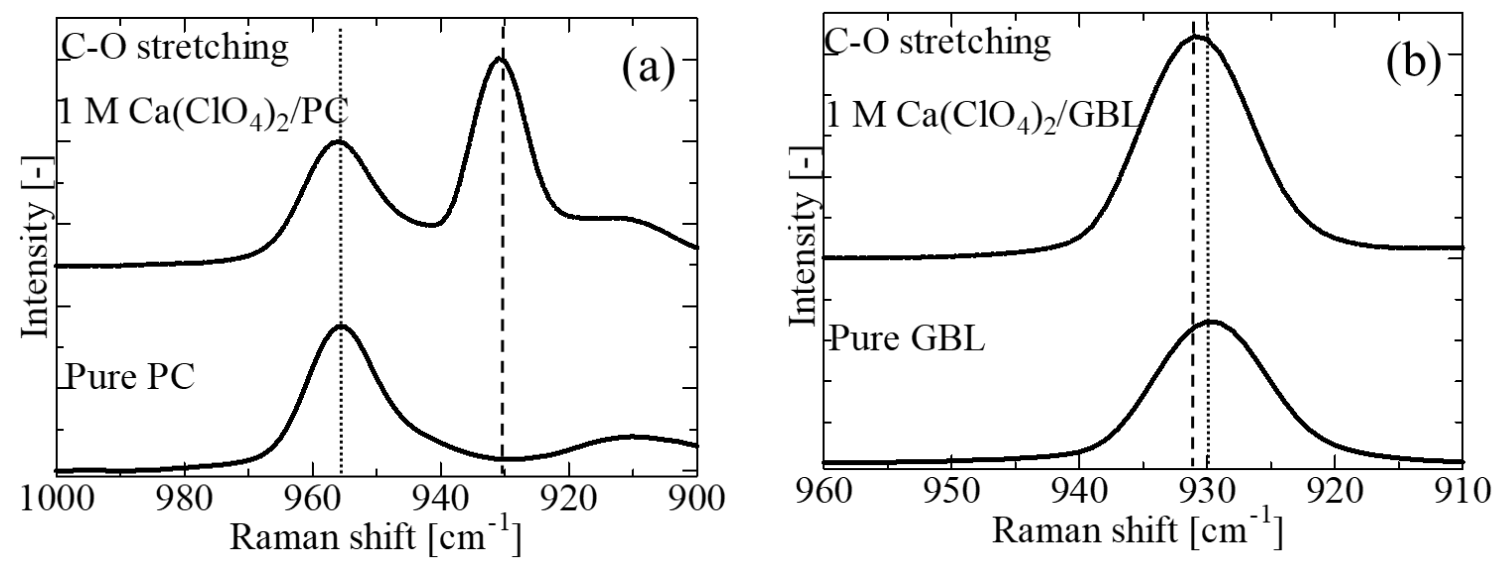

Figure 4 Raman spectra for the symmetric stretching vibration band of $\mathrm{C}-\mathrm{O}$ single bonds in (a) $1 \mathrm{M} \mathrm{Ca}\left(\mathrm{ClO}_{4}\right)_{2} / \mathrm{PC}$ and (b) $1 \mathrm{M} \mathrm{Ca}\left(\mathrm{ClO}_{4}\right)_{2} / \mathrm{GBL}$.

\section{Conclusion.}

High capacitance was obtained by using an electrolyte of $\mathrm{Ca}\left(\mathrm{ClO}_{4}\right)_{2}$.

In the $\mathrm{Ca}^{2+}$ electrolyte, the use of GBL as the solvent resulted high capacitance.

The capacitance increased depending on the specific surface area of electrode materials.

A good electric double layer was formed because the shape of the CV curve did not collapse even when the $\mathrm{Ca}^{2+}$ electrolyte was used.

$\mathrm{Ca}^{2+}$ has a small interaction with GBL and a small number of apparent coordination molecules.

\section{Acknowledgments}

This work was supported by JSPS KAKENHI Grant Number 20K12274.

\section{References}

1. A. Burke, Electrochimica. Acta, 53, (2007) 1083-1091 
2. Cheng Zheng, Masaki Yoshio, Li Qi, Hongyu Wang, Journal of Power Sources, 220 (2012) 169-172

3. Yunpu Zhai, Yuqian Dou, Dongyuan Zhao, Pasquale F. Fulvio, Richard T. Mayes, Sheng Dai, ADVANCED MATERIALS, 23, 42, (2011) 4828-4850

4. Mahdi Alam, Seyed Ahmad Mirbagheri, Mohammad Reza Ghaani, Heliyon, 5, 2, (2019)

5. K. Hiratuka, K. Yamada, Kyon Hun MIN, Electrochemistry, 72, 9 (2004) 706-711

6. T. Yamaguchi, Y. Kimura, and N. Hirota, J. Chem. Phys., 109, 9084 (1998). 